\title{
The Potential Protective Effect of Immunization with Outer-membrane Protein I from Neisseria gonorrhoeae
}

\author{
By J. E. HECKELS, ${ }^{*}$ J. N. FLETCHER $†$ AND M. VIRJI \\ Department of Microbiology, Southampton University Medical School, Southampton General \\ Hospital, Tremona Road, Southampton SO9 4XY, UK
}

(Received 6 March 1989; revised 2 May 1989; accepted 3 May 1989)

\begin{abstract}
Immunization of rabbits with outer membranes (OM) of Neisseria gonorrhoeae produced antibodies directed against outer-membrane proteins PI and PIII. The antibodies directed against PIII reacted equally well on Western blots with all strains tested, but antibodies directed against PI reacted only with the homologous strain. When purified PIB was used for immunization the immune response was quite different: the sera obtained reacted with both homologous and heterologous PIB types and also reacted with strains expressing PIA. Western blotting of peptides produced by sequential cleavage of PIB revealed that the antigenic determinants recognized by anti-OM sera were predominantly located in the central surfaceexposed region of PIB, as is the epitope recognized by the protective anti-PIB monoclonal antibody SM24. In contrast antibodies produced by immunization with purified PI reacted with antigenic determinants in the $\mathrm{N}$-terminal portion of PIB. Nevertheless these determinants are accessible to immune attack on the native protein since the anti-PI sera were opsonic and were strongly bactericidal for both PIA- and PIB-expressing strains.
\end{abstract}

\section{INTRODUCTION}

Protein I (PI) the most abundant outer-membrane protein of the gonococcus, functions as a porin creating a hydrophilic diffusion channel allowing uptake of essential nutrients (Douglas $e t$ al., 1981; Lynch et al., 1984). It may also play an important role in the pathogenesis of gonococcal infection since it can translocate from the outer membrane (OM) into membranes of eukaryotic cells in vitro, a process which may play a crucial role in gonococcal interactions with epithelial cells in vivo (Blake, 1985). These properties, combined with the fact that unlike other major gonococcal surface antigens PI does not undergo antigenic shift during infection (Zak et al., 1984), make it an attractive candidate for inclusion in a potential gonococcal vaccine.

Although PI does not vary within a strain, differences between strains are responsible for antigenic diversity. Immunological and biochemical properties can be used to separate the PI expressed by different strains into one of two main groups, PIA and PIB (Sandstrom et al., 1982). Monoclonal antibodies detect further antigenic differences within the groups which can be used to define a number of different serotypes (Knapp et al., 1984). Despite these antigenic differences structural studies suggest that some domains are more widely shared (Sandstrom $e t$ $a l ., 1982$ ). We have previously described two monoclonal antibodies (mAbs) which together recognized $94 \%$ of the gonococcal strains tested (Fletcher et al., 1986; Virji et al., 1987a).

† Present address : Department of Genetics and Microbiology, University of Liverpool, P.O. Box 147, Liverpool L69 3BX, UK.

$\ddagger$ Present address: Department of Paediatrics, University of Oxford, John Radcliffe Hospital, Headington, Oxford OX3 9DU, UK.

Abbreviations: LPS, lipopolysaccharide; mAb, monoclonal antibody; OM, outer membrane; PI, protein I; PMN, polymorphonuclear leucocyte. 
Antibodies SM24 and SM101 react with conserved epitopes present on PIB and PIA, respectively. Both antibodies protect against the relevant strains in model systems in that they activate complement-mediated bactericidal activity, opsonize for phagocytosis by human polymorphonuclear leucocytes (PMNs) and protect epithelial cells in tissue culture against gonococcal challenge (Virji et al., 1986, 1987a).

The development of effective immunity to PI would require that immunization with PI would induce an immune response to such 'protective' epitopes. In the current study we have further investigated the location of the conserved epitope recognized by antibody SM24, the ability of PIB (both in its native form and after purification) to induce antibodies directed against this epitope and report the potential protective effect of the polyclonal immune response directed against conserved PI epitopes.

\section{METHODS}

Bacterial strains and growth conditions. All bacteria were grown on proteose peptone agar at $37^{\circ} \mathrm{C}$ (Fletcher et al., 1986). The colonial variants of strain $P 9$ have been described previously (Lambden $e t$ al., 1979). Fresh clinical isolates of Neisseria gonorrhoeae were from local sources previously described (Zak et al., 1984). PI type was determined by tryptic digestion (Fletcher et al., 1986) and by serotyping (Knapp et al., 1984; performed by Dr C. Ison, St Mary's Hospital Medical School, London, UK).

$O M$ antigens. $O M$ vesicles were prepared by lithium acetate extraction of gonococci followed by differential centrifugation (Heckels, 1977).

SDS-PAGE. Whole cell bacterial lysates and outer membranes were subjected to SDS-PAGE at a concentration of 5-10 $\mu \mathrm{g}$ per track on gels containing linear gradients of $10-25 \%(\mathrm{w} / \mathrm{v})$ acrylamide. Separated proteins were detected with PAGE Blue 83 (BDH) or were transferred to nitrocellulose sheets for immunological detection (Fletcher $e t$ al., 1986). PI and fragments derived from it were isolated by preparative SDS-PAGE. Gels were placed in $4 \mathrm{M}$-potassium acetate until clear bands could be seen against an opaque background (Higgins \& Dahmus, 1979). Bands corresponding to the polypeptides of interest were excised and subjected to electroelution in $0.1 \%(\mathrm{w} / \mathrm{v}) \mathrm{SDS}$ in $15 \mathrm{mM}-\mathrm{NH}_{4} \mathrm{HCO}_{3}$ (Jacobs \& Cladd, 1986).

Purification of PIA and PIB. PI was extracted from whole cells of strains P9-1 (PIB) and SU70 (PIA) using a method based on that of Blake \& Gotschlich (1984) but with Empigen BB (Albright \& Wilson) as the initial extracting detergent (Virji et al., 1987a). After precipitation with ethanol the crude PI preparations were dissolved in 5\% (w/v) Zwittergent 3-14 (Calbiochem) and purified by ion-exchange chromatography on DEAE Sepharose CL-6B followed by gel filtration through Sephadex G-200 (Blake \& Gotschlich, 1982). With PIB the final product was free from any detectable lipopolysaccharide (LPS), as revealed by carbocyanine dye assay (Janda \& Work, 1971), silver staining (Hitchcock \& Brown, 1983) or dot blotting with an anti-LPS mAb (Virji \& Heckels, 1988), but the PIA contained about $0.1 \%$ LPS which could not be removed by further chromatography.

Tryptic cleavage of PIB. OMs containing PIB were suspended at a concentration of $1 \mathrm{mg}$ protein $\mathrm{ml}^{-1}$ in $50 \mathrm{mM}^{-}$ $\mathrm{NH}_{4} \mathrm{HCO}_{3}, \mathrm{pH}$ 8.0. An equal volume of a solution of $N$-tosyl-L-phenylalanine chloromethyl ketone-trypsin (TPCK-trypsin; Sigma) in the same buffer $\left(10 \mu \mathrm{g} \mathrm{ml}^{-1}\right)$ was added and the mixture was incubated at $37^{\circ} \mathrm{C}$. At regular intervals samples were removed, boiled with an equal volume of dissociating buffer containing $1 \mathrm{~mm}$ phenylmethylsulphonyl fluoride (PMSF), and subjected to SDS-PAGE. Tryptic fragments of PIB were isolated by electroelution as described above.

CNBr cleavage. PI or proteolytic fragments obtained by preparative SDS-PAGE were lyophilized, then a solution of $50 \mathrm{mg} \mathrm{ml}^{-1}$ cyanogen bromide (CNBr; Pierce) in $70 \%(\mathrm{v} / \mathrm{v})$ formic acid was added to give a final protein concentration of about $1 \mathrm{mg} \mathrm{ml}^{-1}$. The solution was incubated at $30^{\circ} \mathrm{C}$ for $16 \mathrm{~h}$ then diluted tenfold with water and lyophilized. The fragments obtained were subjected to SDS-PAGE and Western blotting.

$m A b s$. Details of the immunization, fusion and cloning procedures used for obtaining $m A$ bs directed against PIA and PIB have been described previously (Fletcher et al., 1986; Virji et al., 1987a).

Polyclonal antisera. Purified PIA or PIB was precipitated from detergent by addition of ethanol to $80 \%(\mathrm{v} / \mathrm{v})$ and washed several times with $80 \%$ ethanol. The resulting pellet was suspended in water to a concentration of $200 \mu \mathrm{g}$ $\mathrm{ml}^{-1}$, emulsified with an equal volume of Freund's complete adjuvant (Difco) and $2 \mathrm{ml}$ volumes were injected subcutaneously at four separate sites on rabbits. Booster immunizations with the same antigen in Freund's incomplete adjuvant were given on days 20,40 and 60 , and blood was withdrawn on day 70 . Immunization with purified outer membranes was performed as described previously (Diaz \& Heckels, 1982). Two rabbits were used for each immunization schedule and serum from the one giving the higher ELISA titre with the relevant antigen was used in subsequent experiments.

Investigation of the biological effect of antisera. The bactericidal effect of rabbit antisera was determined in the presence of $10 \%(\mathrm{v} / \mathrm{v})$ human serum as the complement source using PIA or PIB-expressing gonococcal strains resistant to $10 \%$ serum alone (Virji et al., 1986, 1987a). The effect of antibodies in opsonization for phagocytosis by human PMN was determined in a luminol-enhanced PMN chemiluminescence assay (Virji et al., 1986, 1987a). 

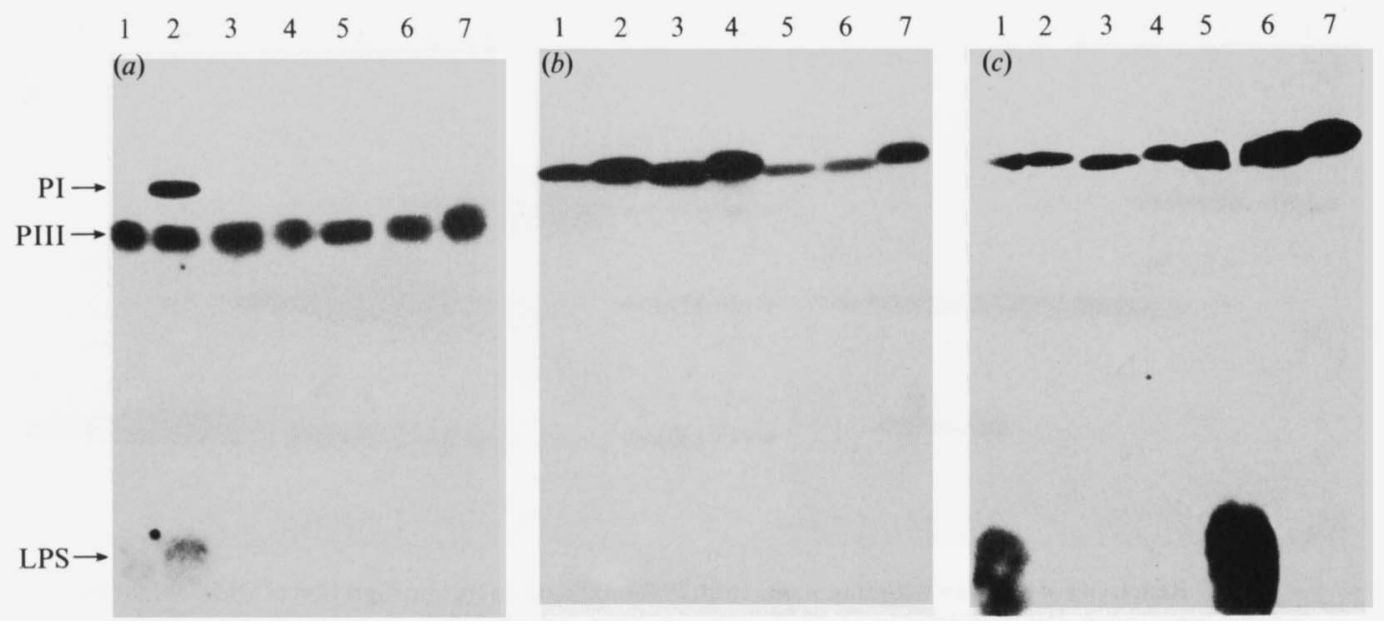

Fig. 1. Cross-reactivity of antibodies in sera raised against OMs and purified PI. Whole-cell lysates from PIB-expressing strains SU79, P9, SU50 and SU72 (tracks 1-4) and PIA-expressing strains SU70, SU87 and SU95 (tracks 5-7) were separated by SDS-PAGE and reacted on Western blots with sera from rabbits immunized with (a) OMs from strain P9, $(b)$ purified PIB from strain P9 and $(c)$ purified PIA from strain SU70.

\section{RESULTS}

\section{Immune response to $P I$}

Sera from rabbits immunized with purified OM complex from PIB-expressing strain P9 reacted on ELISA with OMs from P9 with a titre of $2 \times 10^{6}$ and also with OMs from the PIAexpressing strain SU87, with a titre of $5 \times 10^{5}$. However Western blotting with cell lysates from a number of strains revealed that cross-reactivity was largely due to the presence of antibodies directed against the conserved PIII. Limited cross-reaction was seen between LPS but no reaction with PI from any of the heterologous strains could be observed (Fig. 1a).

In contrast sera raised against the purified PIB reacted on Western blots with a single band corresponding to PI in each of the strains tested. A strong reaction occurred with the strains which expressed PIB including one which lacked the conserved SM24 epitope (Fig. 1b, track 1): In addition, a significant although weaker reaction could also be observed with strains expressing PIA (tracks 5-7). Sera raised against purified PIA also showed a corresponding cross-reaction between the two PI classes although in this case antibodies reacting with LPS from the homologous strain and one heterologous strain were also detected (Fig. 1c).

\section{Location of the conserved antigenic determinants}

Information on the location of antigenic determinants recognized by the rabbit antisera was sought by reacting the sera with fragments produced on proteolytic cleavage of PI. OMs of strain P9 were incubated with trypsin and at intervals samples were removed and subjected to SDSPAGE and Western blotting with anti-P9 OMs and anti-PIB.

Reactivity was found with $26 \mathrm{kDa}$ cleavage product and the secondary $19 \mathrm{kDa}$ peptide derived from it by further proteolysis (Fletcher et al., 1986). Antisera raised against OMs reacted strongly with PI and the $26 \mathrm{kDa}$ fragment, but significantly less strongly with the $19 \mathrm{kDa}$ fragment (Fig. 2a). In contrast, sera raised against PIB reacted strongly with both the $26 \mathrm{kDa}$ and $19 \mathrm{kDa}$ bands (Fig. $2 b$ ). Similar strong reactivity with the 26 and $19 \mathrm{kDa}$ fragments was also seen when the anti-PIB was reacted with trypsin-treated OMs from a heterologous strain (not shown).

Previous studies with mAb SM24 demonstrated reactivity with the $26 \mathrm{kDa}$ fragment but not the $19 \mathrm{kDa}$ fragment. To confirm the location of the SM24 epitope, the $26 \mathrm{kDa}$ partial trypsin cleavage product was purified by preparative SDS-PAGE and subjected to cleavage with 


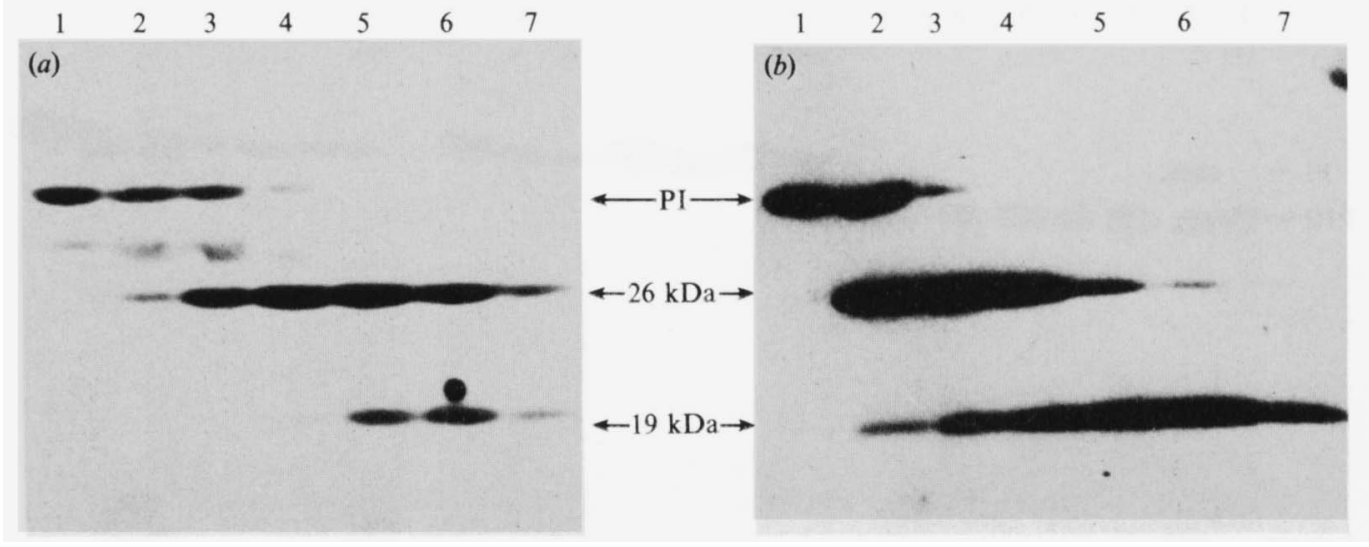

Fig. 2. Reactivity of antisera with fragments from PIB produced on tryptic digestion of OMs. Strain P9 OMs were incubated with trypsin at $37^{\circ} \mathrm{C}$, samples were removed at $0,1,5,15,30,60$ and $90 \mathrm{~min}$ (tracks 1-7, respectively) and subjected to SDS-PAGE. Western blots were reacted with (a) anti-OM and $(b)$ anti-PIB sera. Arrows show the position of intact PIB, the initial $26 \mathrm{kDa}$ cleavage product and the $19 \mathrm{kDa}$ fragment derived from it by further proteolysis.

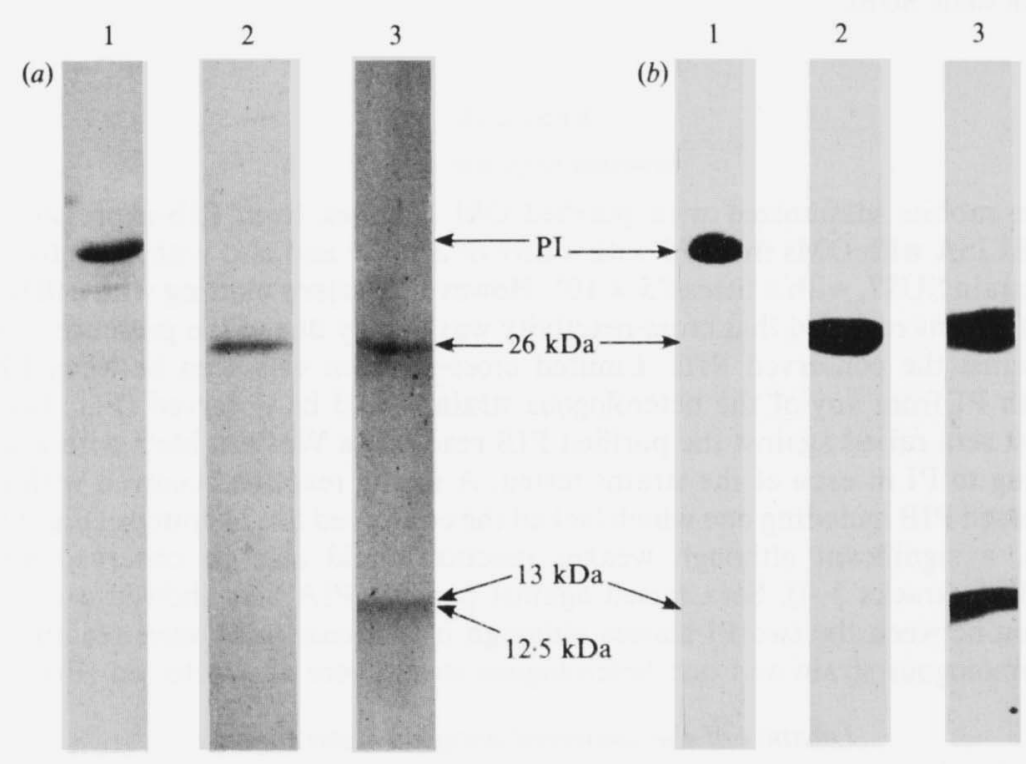

Fig. 3. Reaction of mAb SM24 with the central peptide produced by sequential tryptic and $\mathrm{CNBr}$ cleavage of PIB. OMs of strain P9 were treated with trypsin at $37^{\circ} \mathrm{C}$ and the $26 \mathrm{kDa}$ fragment was isolated by preparative SDS-PAGE and subjected to cleavage with CNBr. Lane 1, purified PI: lane 2, $26 \mathrm{kDa}$ fragment; lane 3, $26 \mathrm{kDa}$ fragment after cleavage with $\mathrm{CNBr}$. (a) Gel of resulting fragments stained with PAGE Blue (BDH); (b) Western blot with mAb SM24. Arrows show positions of PI, $26 \mathrm{kDa}, 13 \mathrm{kDa}$ and $12.5 \mathrm{kDa}$ fragments.

CNBr. SDS-PAGE revealed the production of two poorly resolved fragments of approximately $12.5 \mathrm{kDa}$ and $13 \mathrm{kDa}$ (Fig. $3 a$ ). Western blotting with SM24 showed reactivity in the region apparently corresponding to the position of the $13 \mathrm{kDa}$ fragment (Fig. $3 b$ ).

\section{Protective effect of anti-PI polyclonal sera}

Opsonization. The opsonic activity of the anti-PI sera was investigated using a luminolenhanced chemiluminescence system. Since isolates which express PII are readily phagocytosed 

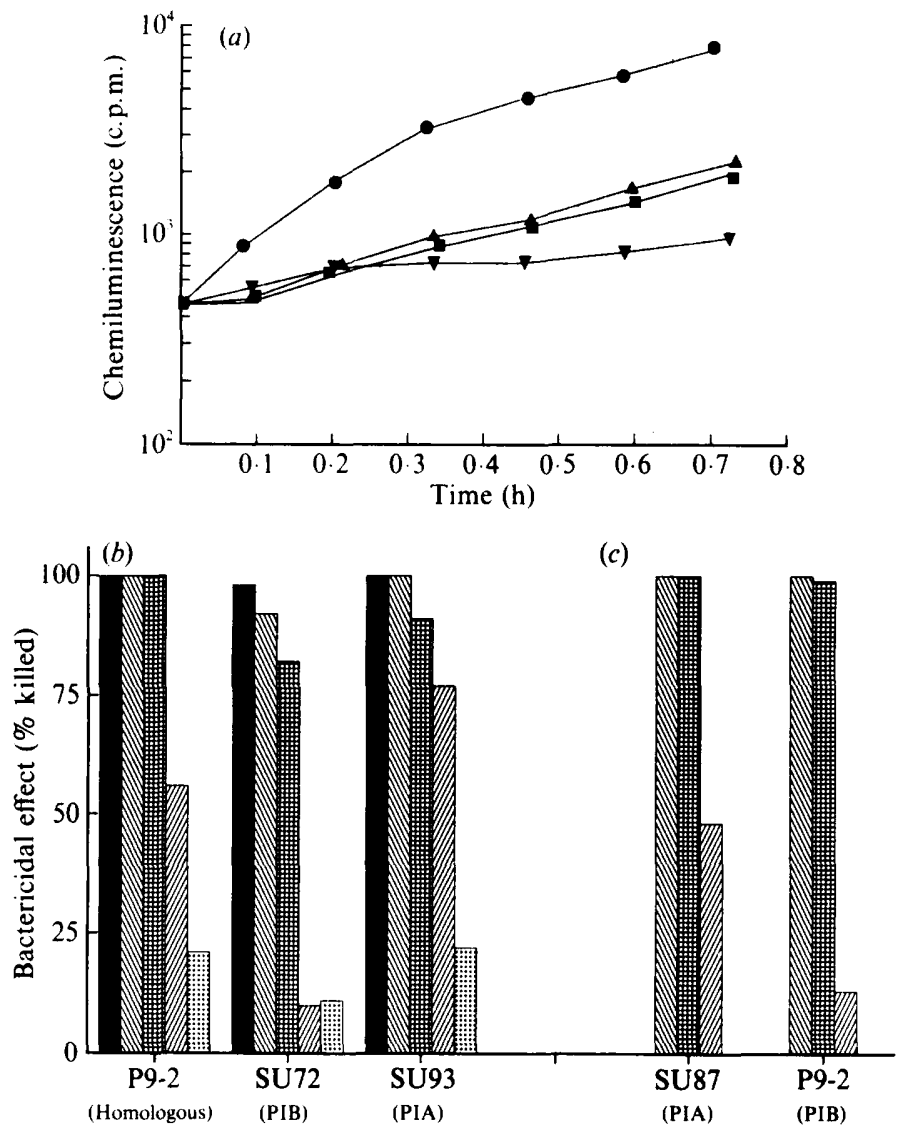

Fig. 4. Protective effect of anti-PI antisera. (a) Opsonization of strain P9: comparative effect in luminol-enhanced chemiluminescence of anti-PIB (A), anti-PIA $(\square)$, mAb SM24 $(O)$ and control containing a non-opsonic anti-PIII mAb $(\nabla)$. Experiments were performed on at least three separate occasions; data shown are from one typical experiment. (b) Bactericidal effect of anti-PIB on homologous strain P9, heterologous PIB-expressing strain SU72, and PIA-expressing strain SU93. Antibody dilutions used were $1: 40 \square, 1: 200 \mathbb{N}, 1: 1000$ 团, 1:5000 $\mathbb{Z}$ and $1: 25000$. effect of anti-PIA on heterologous PIA-expressing strain SU87 and PIB-expressing strain P9-2. Antibody dilutions used were $1: 100 \mathbb{N}, 1: 1000$ 团, and $1: 10000 \mathbb{Z}$. In all bactericidal experiments containing either complement alone or complement plus unimmunized rabbit sera showed killings of $<10 \%$.

and killed by PMN, even in the absence of antibody (Virji \& Heckels, 1986), the PII- variant of the homologous strain was used. The polyclonal sera produced a significant increase in chemiluminescence compared with a non-opsonic mAb directed against PIII (Virji et al., 1987b) although it was not as effective as monoclonal antibody SM24 (Fig. 4a).

Bactericidal effect. The potential bactericidal effect of anti-PIB was tested against three gonococcal strains resistant to killing by fresh human serum. In the presence of the antiserum the homologous strain P9, a heterologous PIB-expressing strain and a PIA-expressing strain were all effectively killed at a serum dilution of $1: 1000$ and a significant bactericidal effect could still be observed at a dilution of $1: 25000$ (Fig. $4 b$ ).

The serum raised against PIA was also bactericidal for its homologous strain but this could not be ascribed to a specific anti-PI effect due to the presence of the anti-LPS antibodies detected in Western blotting. The serum was therefore tested against two heterologous strains which had been shown by Western blotting to have antigenically distinct LPS, the PIA-expressing strain SU87 and the PIB-expressing strain P9. In both cases the serum was also strongly bactericidal, confirming the cross-reacting bactericidal effect of anti-PIA (Fig. 4c). 


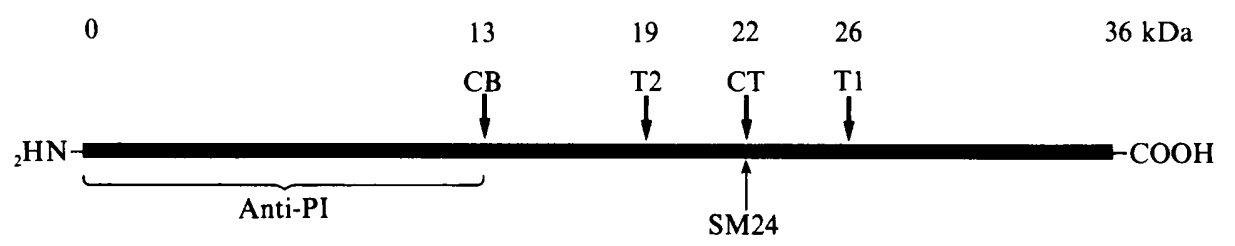

Fig. 5. Location of conserved antigenic determinants on PIB. Diagrammatic representation of the location of cleavage sites on PIB showing relative positions (in $\mathrm{kDa}$ from N-terminus) of initial and secondary cleavage sites with trypsin (T1, T2), CNBr (CB) and chymotrypsin (CT) and fragments reacting with $\mathrm{mAb}$ SM24 and anti-PIB.

\section{DISCUSSION}

Most of the major surface antigens of the gonococcus, such as pili, protein II and LPS, are subject to phase and/or antigenic variation enabling the bacteria to avoid much of the consequence of the host immune response, and rendering them unlikely targets for vaccination. In contrast the role of PI as a porin in maintenance of gonococcal viability appears to ensure its stable expression on the bacterial surface. Despite the existence of only two main classes of PI, structural variations are responsible for generating a relatively large number of different serovars (Sandstrom et al., 1982). Nevertheless studies with mAbs demonstrate the potential ability of both PIA and PIB to induce a broadly cross-reacting protective immune response. Although the previous studies with mAbs were carried out with immunization schedules designed to boost the immune response to shared antigenic determinants, only two crossreacting mAbs were obtained, SM24 and SM101, recognizing PIB- and PIA-expressing strains, respectively (Fletcher et al., 1986; Virji et al., 1987a). Since this suggests that any conserved epitopes in the native protein may be poorly immunogenic, the current studies were carried out with the aim of investigating the potential of conserved epitopes, particularly that recognized by $\mathrm{mAb}$ SM24, for inducing a polyclonal immune response.

Problems of producing effective immunity to gonococci were illustrated when animals were immunized with outer membranes; the antibodies directed against PI reacted only with the homologous strain, whilst potentially blocking antibodies directed against PIII (Rice et al., 1986; Virji et al., 1988) which reacted with all the strains tested were also induced. One strategy to avoid the potential problems created by the response to PIII is to use purified PI for immunization rather than the OM complex. However the methods of purification of PI which utilize ion-exchange and size-exclusion chromatography in the presence of zwitterionic detergents retain PI in a native conformation (Blake \& Gotschlich, 1982), so that immunization with the detergent micelles containing the protein would also be expected to induce largely serotype-specific antibodies. Similarly previous immunization studies have been carried out with purified PI incorporated into liposomes or iscoms which also present PI to the immune system in its native conformation (Wetzler et al., 1988; Kersten et al., 1988). In the current study an attempt was made to remove detergents from PI by repeated cycles of solubilization and precipitation. When this material was used for immunization the response was quite different to that obtained with OMs. The serum obtained by immunization with PIB from strain P9 reacted equally well with homologous and heterologous PIB types and also reacted, although to a lesser extent, with PIA.

Although the initial aim was to investigate the potential immunogenicity of the SM24 epitope, the antigenic determinants recognized by the polyclonal anti-PIB serum clearly differ from this. Previous results have suggested that the conserved epitope recognized by mAb SM24 is located on a central, surface-exposed portion of the PIB molecule, since reactivity is abolished when a central $7 \mathrm{kDa}$ portion of the molecule is removed by partial tryptic digestion (Fletcher et al., 1986). Subsequently repeated attempts to isolate a peptide containing the epitope have failed, suggesting that further proteolytic cleavage occurs after the $7 \mathrm{kDa}$ peptide is released into solution (unpublished observations). However sequential cleavage of the PIB molecule by partial trypsin digestion followed by $\mathrm{CNBr}$ has now confirmed the central location of the SM24 epitope (Fig. 5). In contrast the reaction of the anti-PIB with the $19 \mathrm{kDa}$ fragment produced by 
extensive trypsin digestion of OMs shows that conserved determinants recognized lie predominantly towards the N-terminal portion of the molecule. Presumably the purified PI adopts a quite different conformation from the native protein, altering the potential immunogenicity of normally non-immunogenic regions. Clearly, antibodies produced following manipulations of the protein which expose such regions might be expected to fail to react with the native protein itself. Immunization with PI either adsorbed onto aluminium hydroxide or denatured with SDS has been reported to induce anti-PI antibodies which do not react with OMs (Wetzler et al., 1988; Teerlink et al., 1987). Indeed the suggested model of PIB organization with only the central, protease-sensitive region exposed on the gonococcal surface (Barrera \& Swanson, 1984; Blake, 1984) would predict that the N-terminal portion of PIB recognized by the anti-PIB sera would be buried in the membrane and hence not susceptible to immune attack. However the anti-PIB antibodies clearly recognize surface-exposed domains, since they were opsonic and highly bactericidal in the presence of complement, not only for heterologous PIBexpressing strains but also for PIA-expressing strains. Similarly the antiserum raised against PIA is also bactericidal against PIB-expressing strains. Thus, immunization with the purified proteins is considerably more effective in producing a cross-reactive and protective immune response than could have been anticipated from any previous studies.

Thus it appears that the normal immune response to native PI is directed against the central portion of the molecule resulting in a largely type-specific immune response and that conserved epitopes in the same region, such as that recognized by mAb SM24, are relatively nonimmunogenic. However the N-terminal portions of both PIA and PIB also contain surfaceexposed regions which are accessible for antibody binding, but at least in the case of PIB, these are normally non-immunogenic. Although in conflict with the previous model (Blake, 1985) the similarity in structure and orientation between PIA and PIB suggested by these experiments is in accord with recent studies involving the cloning and sequencing of genes responsible for expression of both proteins (Gotschlich et al., 1987; Carbonetti et al., 1987). These have revealed that PIA and PIB have much of their amino acid sequence in common and that viable genetic constructs can be produced which express hybrid PIA/PIB molecules (Carbonetti et al., 1988), suggesting that the two protein classes are unlikely to have radically different orientations in the OM.

The ability to induce a bactericidal immune response directed against multiple serotypes of PI is an important step in vaccine design and may be particularly important in prevention of the complications associated with gonococcal infection. Bactericidal antibodies directed against PI are produced in response to gonococcal salpingitis and appear to protect against reinfection by strains of the same serotype (Buchanan et al., 1980). The production of cross-reacting and bactericidal anti-PI antibodies could therefore be expected to protect against most if not all strains. However the presentation of the antigen and the adjuvant used for immunization appear to be critical since other workers have failed to induce protective cross-reacting antibodies (Wetzler et al., 1988; Teerlink et al., 1987). Although the schedule used here is clearly inappropriate for human vaccination, and further work will be required to investigate effective presentation to the immune system, the current studies demonstrate the potential for immunization strategies designed to induce antibodies directed against highly conserved antigenic determinants on PI.

This work was supported by a MRC project grant.

\section{REFERENCES}

Barrera, O. \& Swanson, J. (1984). Proteins IA and IB exhibit different surface exposures and orientations in the outer membrane of Neisseria gonorrhoeae. Infection and Immunity 44, 565-568.

BLAKE, M. S. (1985) Implications of the active role of gonococcal porins in disease. In The Pathogenic Neisseria, pp. 251-258. Edited by G. Schoolnik. Washington, DC: American Society for Microbiology.
Blake, M. S. \& Gotschlich, E. C. (1982). Purification and partial characterization of the major outer membrane protein of Neisseria gonorrhoeae. Infection and Immunity 36, 277-283.

Blake, M. S. \& Gotschlich, E. C. (1984). The purification and partial characterization of the opacity-associated proteins of Neisseria gonorrhoeae. Journal of Experimental Medicine 159, 452-462.

Buchanan, T. M., Eschenbach, D. A., KNapP, J. S. \& 
Holmes, K. K. (1980). Gonococcal salpingitis is less likely to recur with Neisseria gonorrhoeae of the same principal outer membrane protein antigen type. American Journal of Obstetrics and Gynecology 138, 978-980.

Carbonetti, N. H. \& Sparling, P. F. (1987). Molecular cloning and characterization of the structural gene for protein I, the major outer membrane protein of Neisseria gonorrhoeae. Proceedings of the National Academy of Sciences of the United States of America 84, 9084-9088.

Carbonetti, N. H., Simmad, V. L., Seifert, H. S. \& So, M. (1988). Genetics of protein I of Neisseria gonorrhoeae: construction of hybrid porins. Proceedings of the National Academy of Sciences of the United States of America 85, 6841-6845.

Diaz, J.-L. \& Heckels, J. E. (1982). Antigenic variation of outer membrane protein II in colonial variants of Neisseria gonorrhoeae P9. Journal of General Microbiology 128, 585-591.

douglas, J. T., LeE, M. D. \& Nikaido, H. (1981). Protein I of Neisseria gonorrhoeae outer membrane is a porin. FEMS Microbiology Letters 12, 305-309.

FLETCHER, J. N., ZAK, K., VIRJI, M. \& HeCKels, J. E. (1986). Monoclonal antibodies to gonococcal outer membrane protein $\mathrm{I}$ : location of a conserved epitope on protein IB. Journal of General Microbiology 132, 1611-1620.

Gotschlich, E. C., Seiff, M. E., Blake, M. S. \& COOMEY, M. (1987). Porin protein of Neisseria gonorrhoeae: cloning and gene structure. Proceedings of the National Academy of Sciences of the United States of America 84, 8135-8139.

HeCkels, J. E. (1977). The surface properties of Neisseria gonorrhoeae: isolation of the major components of the outer membrane. Journal of General Microbiology 99, 333-341.

Higgins, R. C. \& Dahmus, M. E. (1979). Rapid visualisation of protein bands in preparative SDSpolyacrylamide gels. Analytical Biochemistry 93,257 260.

Hitchcock, P. J. \& Brown, T. M. (1983). Morphological heterogeneity among Salmonella lipopolysaccharide chemotypes in silver-stained polyacrylamide gels. Journal of Bacteriology 154, 269-277.

JACOBS, E. \& ClAD, A. (1986). Electroelution of fixed and stained membrane proteins from preparative sodium dodecyl sulphate-polyacrylamide gels into a membrane trap. Analytical Biochemistry 154, 583598.

JANDA, J. \& WORK, E. (1971). A colorimetric estimation of lipopolysaccharides. FEBS Letters 16, 343345.

Kersten, G. F. A., Teerlink, T., Derks, H. J. G. M., VerleiJ, A. J., Van Wezel, T. L., Crommelin, D. J. A. \& BEUVERY, E. C. (1988). Incorporation of the major outer membrane protein of Neisseria gonorrhoeae in saponin-lipid complexes (iscoms): chemical analysis, some structural features, and comparison of their immunogenicity with three other antigen delivery systems. Infection and Immunity 56, 432-438.

KnapP, J. S., TaM, M. R., Nowinski, R. C., Holmes, K. K. \& Sandstrom, E. G. (1984). Serological classification of Neisseria gonorrhoeae with use of monoclonal antibodies to gonococcal outer mem- brane Protein I. Journal of Infectious Diseases 150 , 44-48.

LAMbden, P. R., HeCkels, J. E., James, L. T. \& WATT, P. J. (1979). Variations in surface protein composition associated with virulence properties in opacity types of Neisseria gonorrhoeae. Journal of General Microbiology 114, 305-312.

LyNCh, E. C., Blake, M. S., Gotschlich, E. C. \& MAURO, A. (1984). Studies of porins: spontaneously transferred from whole cells of Neisseria gonorrhoeae and Neisseria meningitidis. Biophysical Journal 45, 109-117.

Rice, P. A., Vayo, H. E., Tam, M. R. \& Blake, M. S. (1986). Immunoglobulin $G$ antibodies directed against protein III block killing of serum resistant Neisseria gonorrhoeae by immune serum. Journal of Experimental Medicine 164, 1735-1748.

Sandstrom, E. G., Chen, K. C. S. \& Buchanan, T. M. (1982). Serology of Neisseria gonorrhoeae: co-agglutination serogroups WI and WII/III correspond to different outer membrane protein molecules. Infection and Immunity 38, 462-470.

TeERlink, T., VersantVoort, H. \& Beuvery, E. C. (1987). Antigenic and immunogenic properties of cyanogen bromide peptides from gonococcal outer membrane Protein IB. Journal of Experimental Medicine 166, 63-76.

VIRII, M. \& HeCKeLS, J. E. (1986). The effect of protein II and pili on the interaction of Neisseria gonorrhoeae with human polymorphonuclear leucocytes. Journal of General Microbiology 132, 503-512.

VIRJI, M. \& HECKELS, J. E. (1988). Nonbactericidal antibodies against Neisseria gonorrhoeae: evaluation of their blocking effect on bactericidal antibodies directed against outer membrane antigens. Journal of General Microbiology 134, 2703-2711.

VIRJ, M., ZAK, K. \& HeCKELS, J. E. (1986). Monoclonal antibodies to gonococcal outer membrane protein IB: use in the investigation of the potential protective effect of antibodies directed against conserved and type-specific epitopes. Journal of General Microbiology 132, 1621-1629.

VIRJi, M., Fletcher, J. N., ZAK, K. \& Heckels, J. E. $(1987 a)$. The potential protective effect of monoclonal antibodies to gonococcal outer membrane protein IA. Journal of General Microbiology 133, 2639-2646.

VIRJ, M., ZAK, K. \& HeCKels, J. E. (1987b). Outer membrane protein III of Neisseria gonorrhoeae: variations in biological properties of antibodies directed against different epitopes. Journal of General Microbiology 133, 3393-3401.

Wetzler, L. M., Blake, M. S. \& Gotschlich, E. C. (1988). Characterization of antibodies raised to Protein I (PI) of Neisseria gonorrhoeae by injection with PI-liposome constructs. In Gonococci and Meningococci, pp. 457-463. Edited by J. T. Poolman, H. C. Zanen, T. F. Meyer, J. E. Heckels, P. R. H. Makela, H. Smith \& E. C. Beuvery. Dordrecht: Kluwer Academic Publishers.

ZaK, K., Diaz, J.-L., Jackson, D. \& Heckels, J. E. (1984). Antigenic variation during infection with Neisseria gonorrhoeae: detection of antibodies to surface proteins in sera of patients with gonorrhoea. Journal of Infectious Diseases 149, 166-173. 